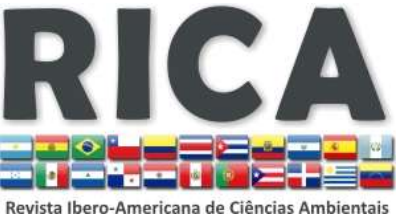

Journals Homepage:

www.sustenere.co/journals

\section{PERCEPČ̃̃ DE ALUNOS DE ESCOLAS PÚBLICAS SOBRE RECICLAGEM: FERRAMENTAS DE INICIAÇÃO A EDUCAÇÃO AMBIENTAL}

\section{RESUMO}

Este estudo pretende disseminar a educação ambiental nos alunos do $6^{\circ}$ ao $9^{\circ}$ ano do ensino fundamental de escolas públicas da cidade do Rio de Janeiro, buscando conscientizá-los sobre os aspectos ambientais em torno da coleta seletiva e do reaproveitamento desses materiais. Foi elaborado um material educativo como uma ferramenta de iniciação à educação ambiental constituído de uma cartilha sobre reciclagem de papel baseado nas informações dadas pelos próprios alunos e ainda, uma oficina de reciclagem onde os alunos podem vivenciar a experiência prática de reciclar materiais. No final desse estudo foi realizado um levantamento com o objetivo de analisar o grau de aceitação do treinamento e a possível replicação dos conhecimentos adquiridos. Os dados analisados evidenciaram que $100 \%$ dos alunos, gostaram de ter participado da oficina de reciclagem de papel e os mesmos acreditam ser possível reproduzi-la nas suas residências, utilizando o material de apoio fornecido. Desta forma, concluiu-se que o material proposto serviu para estimular os alunos das escolas públicas do Rio de Janeiro à prática da educação ambiental, formando multiplicadores para a consolidação do processo de sustentabilidade.

PALAVRAS-CHAVES: Reciclagem de Papel; Educação Ambiental; Materia Educativo; Escola Pública.

\section{PERCEPTION OF STUDENTS IN PUBLIC SCHOOLS ABOUT RECYCLING: TOOLS OF INITIATION ENVIRONMENTAL EDUCATION}

\section{ABSTRACT}

This study intends to disseminate environmental education in students from elementary education at public schools in the Rio de Janeiro city, seeking them aware of environmental issues around the selective collection and recycling of these materials. An educational materials as a tool for introduction to environmental education was prepared. It consists of a primer on paper recycling based on the information given by the students themselves and even a recycling workshop where students can experience the practical of recycling materials. At the end of this study a survey aimed at examining the degree of acceptance of training and the possible replication of the knowledge acquired was performed. The analyzed data showed that $100 \%$ of the students liked to have participated in the paper recycling workshop and the students believe that they can play it at home, using the educational material provided. Thus, it was concluded that the material proposed is to encourage students from public schools in Rio de Janeiro the practice of environmental education, forming multipliers to the consolidation of the sustainability process.

KEYWORDS: Paper Recycling; Environmental Education; Educational Materials; Public School.
Revista Ibero-Americana de

Ciências Ambientais, Aquidabã, v.6, n.1, Dez 2014, Jan, Fev, Mar, Abr, Mai 2015.

ISSN 2179-6858

SECTION: Articles

TOPIC: Educação Ambiental

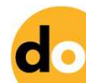

DOI: 10.6008/SPC2179-6858.2015.001.0005

Robson da Silva Teixeira

Universidade Federal do Rio de Janeiro, Brasil http://lattes.cnpq.br/5359994634728097 teixeira@if.ufri.br

Rodrigo Otavio Lopes de Souza Centro Universitário Augusto Motta, Brasil http://lattes.cnpq.br/73764444559440311 digootavio@gmail.com

Received: 03/12/2014

Approved: 14/10/2015

Reviewed anonymously in the process of blind peer.

Referencing this:

TEXEIRA, R. S.; SOUZA, R. O. L.. Percepção de alunos de escolas públicas sobre reciclagem: ferramentas de iniciação a educação ambiental. Revista Ibero-

Americana de Ciências Ambientais, Aquidabã, v.6, n.1, p.57-64, 2015. DOl:

http://dx.doi.org/10.6008/SPC2179$\underline{6858.2015 .001 .0005}$ 


\section{INTRODUÇÃO}

A sustentabilidade é um termo que vem sendo inserido atualmente em diversos discursos como fórmula de solução para o combate aos problemas relativos à preservação e renovação do ambiente. A tentativa de modificar um quadro ambiental crítico é a força motriz para uma série de programas e projetos de combate à poluição, a defesa de ecossistemas e a inclusão social. No entanto, não se percebe um direcionamento desses programas aos alunos do ensino fundamental das escolas públicas da cidade do Rio de Janeiro.

A sociedade brasileira no campo da reciclagem se encontra numa fase inicial, carecendo de maior consciência sobre a importância do reaproveitamento dos resíduos sólidos. Especificamente tratando da coleta e reciclagem de papel, nas suas diferentes formas, observa-se uma contribuição muito baixa da população devido ao reduzido valor agregado deste insumo e a difícil manipulação e seleção deste resíduo. Em 2012, segundo a Indústria Brasileira de Árvores (IBÁ) ligada à Associação Brasileira de Papel e Celulose (BRACELPA), a taxa de recuperação de papel era de $45,7 \%$, cerca de 7.000 toneladas (IBÁ, 2014).

Adicionalmente, estima-se que para cada tonelada de papel picado reciclado pelo menos 22 árvores deixam de ser cortadas (ADAMS, 2003). Portanto, conscientizar estudantes do ensino fundamental na faixa etária dos 10 aos 14 anos, mostrando a necessidade de se estabelecer uma rotina de ações sustentáveis é a motivação deste trabalho. Esta nova geração tem a capacidade de propagar informações com uma dinâmica muito particular que pode e deve culminar com o desenvolvimento do planeta. A partir desta abordagem, buscou-se garantir a disseminação da proposta de desenvolvimento sustentável através da reciclagem; fazendo com que o cidadão entre em sintonia com o movimento global de proteção ambiental e expansão sem esgotamento dos recursos naturais.

A Reciclagem de papel contribui como uma ação sustentável que pretende reduzir o desmatamento e o uso irresponsável dos recursos naturais, contribuindo para a redução do aquecimento global, potencializando o sequestro de carbono e outros fatores. Portanto, as atividades relacionadas a reciclagem de papel podem se transformar em ações que promovam a participação ativa do alunos inserindo-os no próprio processo de aprendizagem pois, encontrar ferramentas de ensino que possam deixar o processo de ensino-aprendizagem mais motivador tem sido uma das grandes dificuldades para os professores de nível fundamental e médio.

A partir do exposto, este estudo pretendeu apresentar a prática da reciclagem como um instrumento de transformação benéfico para o indivíduo que a realiza, para a sociedade e para o ambiente. Para tanto, foram mobilizados alunos de uma escola pública do estado do Rio de Janeiro que participaram na elaboração de material didático com linguagem apropriada, de forma que a temática da coleta seletiva e da reciclagem fosse abordada de forma mais sólida e objetiva. Adicionalmente, uma oficina de reciclagem foi realizada de modo que os alunos concretizassem a 
capacitação associando a prática aos conceitos teóricos sobre sustentabilidade e, favorecendo em longo prazo, a educação ambiental.

\section{REVISÃO TEÓRICA}

\section{As Questões Ambientais e a Escola de Nível Fundamental}

O artigo 225 da Constituição Federal brasileira assegura a todos os brasileiros o direito ao meio ambiente ecologicamente equilibrado como bem coletivo, indicando ainda o dever de todas as esferas à defesa deste meio para às presentes e as futuras gerações. Determina ainda que o Estado cumpra a sua função social, atendendo simultaneamente ao aproveitamento racional e adequado dos recursos naturais disponíveis e a preservação do meio ambiente. Dentro dessas premissas, acredita-se que essas ações possibilitam a construção do entendimento de que uma "Escola do Futuro" é aquela que realiza no presente, de forma consciente, ações que criam um futuro desejado e sustentável. Portanto, espera-se que ao implantar atividades educativas voltadas a preservação do ambiente em escolas públicas haja uma transformação do sistema de forma que os professores possam ensinar os alunos a ampliar suas habilidades (SKINNER, 1991).

Lugares onde haja uma forma de ensino eficiente, onde os estudantes serão motivados a buscar seus assuntos de interesse e observarão nos professores o papel de supervisores e não mais de detentores do conhecimento. Portanto, buscar uma escola pública que ofereça ações sustentáveis, a partir de atividades educativas pode contribuir para que ela se transforme numa escola mais integradora, em que os alunos participam, interrogam e descobrem valores. Souza (2005, p. 5) acredita que a estimulação e troca de experiências favorece a educação pautada nas ações sustentáveis que não se limitam aos aspectos teóricos, mas a compreensão do que é viver em um mundo sustentável.

Isto reforça que a informação sobre sustentabilidade vai além do conhecimento científico, abrangendo o conhecimento vivido e as experiências sobre esse assunto. Com relação à utilização de materiais educativos e oficinas, Loures (2009), acredita que essas práticas devem ser consideradas na nova educação brasileira, ou seja, aquela centrada na interação humana, que pode preparar os alunos para a vida e posicioná-los como co-criadores do sistema de ensino, estimulando-os a se apropriarem de seu futuro em um ambiente desafiador e ao mesmo tempo inovador, pois gera múltiplos caminhos e oportunidades que permitem ao aluno anteciparem às mudanças, tirando proveito delas, em vez de temê-las.

Souza (2010) afirma que toda prática educacional que aumente a eficiência e melhore os resultados do ensino é positiva. No entanto, Barbosa (2004) afirma que a prioridade deve estar na valorização dos seres humanos envolvidos no processo educacional, sejam eles professores, alunos ou familiares.

Melo (2007) relata a escassez das ações educativas voltadas para a promoção e proteção do planeta. Descreve ainda que a falta de prioridade das atividades educativas pode ser explicada 
pela compreensão, por parte dos profissionais da educação, que informação e educação em sustentabilidade estão relacionadas à informação teórica e não as atividades param e com a comunidade. Percebe-se, entretanto, que os problemas ambientais estão presentes no cotidiano de todo cidadão. Eles, inevitavelmente, surgem da interação do ser humano com a natureza, como consequência do desenvolvimento humano, do consumo de energia e do consumo dos recursos naturais, principalmente os nãos renováveis.

Desta forma, dada a emergência desses problemas, é mister que essas questões ambientais sejam abordadas o mais cedo possível no sentido de gerar uma conscientização coletiva. Uma das formas de levar este tipo de conscientização à comunidade é pela ação direta na escola, através de diversas que levem os alunos a reflexão crítica a fim de aumentar a compreensão dos problemas da comunidade onde vivem, auxiliando-os a combater ações que desrespeitam e, muitas vezes, impactam negativamente nas suas próprias vidas.

Nesse sentido, quanto mais cedo à educação ambiental for tratada na escola, mais efetiva será a participação desses alunos na sociedade. Inicialmente, com atitudes dentro de suas próprias casas, respeitando suas famílias e, posteriormente, na sociedade na qual estão inseridos. No Brasil, estes aspectos já são estabelecidos na Constituição através da Lei 9.795, de 27 de abril de 1999 (Lei 9.705/99), que dispõe sobre a educação ambiental (EA), e institui a Política Nacional de Educação Ambiental (PNEA) que determina que: a educação ambiental é um componente essencial e permanente da educação nacional, devendo estar presente, de forma articulada, em todos os níveis e modalidades do processo educativo, em caráter formal e não-formal (BRASIL, 1999).

\section{METODOLOGIA}

A pesquisa de campo foi desenvolvida no Centro Integrado de Educação Pública (CIEP) Professor César Pernetta localizado no complexo da Maré, zona norte do Rio de Janeiro. Esta instituição do Estado possui em torno de 1100 alunos distribuídos entre o ensino fundamental e médio, em dois turnos. A pesquisa envolveu 74 alunos voluntários do $9^{\circ}$ ano do ensino fundamental, no período de 12 a 21 de março de 2014, sendo os dados coletados e tratados utilizando a estatística descritiva.

Para a elaboração de um material educativo adequado à realidade dos alunos de escolas públicas do Estado do Rio de Janeiro, foi necessário levantar dados através de um questionário produzido pelo próprio autor que pretendeu observar o nível de conhecimento dos alunos sobre a prática da reciclagem e a linguagem mais adequada ao público alvo.

Quanto ao procedimento norteador desta pesquisa, cumpre dizer que a obtenção de dados sobre o grau de conhecimento a respeito da educação ambiental ocorreu mediante contato direto e interativo do pesquisador com os alunos do ensino fundamental que se dispusera a contribuir com este trabalho. A escolha da faixa etária se deu em função dos alunos já terem condições de 
propagarem as informações adquiridas, pois nessa fase, o cidadão está buscando se integrar a grupos sociais e encara com naturalidade as práticas de ensino inovadoras.

Inicialmente, foi realizada uma validação do questionário (pré-teste), durante dois dias consecutivos, a um grupo de 19 alunos com as mesmas características da população estudada. $\mathrm{O}$ objetivo desta etapa foi avaliar o processo de coleta e tratamento dos dados, além de aumentar a interação entre o pesquisador e os alunos, de forma que houvesse a familiarização do pesquisador com as experiências pessoais, com o discurso e com os significados que os alunos atribuem à vida. Esse estudo de campo, no ambiente natural dos sujeitos investigados, ou seja, no local de origem dos dados, é peculiaridade da pesquisa qualitativa capaz de oferecer uma melhor interpretação do elemento central do estudo (NEVES, 1996; POPE \& MAYS, 2005; RICHARDSON et al., 2009).

A partir desta validação, a pesquisa foi dividida em três etapas: entrevista semi-estruturada validada com os 74 alunos; elaboração de material educativo e; oficina de capacitação e educação ambiental através da prática da reciclagem de papel. Esta metodologia será pautada na construção compartilhada do conhecimento (VALLA \& STOTZ, 1993), do processo educativo como pedagogia da autonomia (FREIRE, 1996) e da educação como fonte para participação social e cidadania (SANTOS, 2010). Na primeira etapa, o questionário foi subdividido em três partes: três questões relativas à identificação do aluno (colher dados sobre a predominância do sexo na pesquisa e a idade dos entrevistados); quinze questões direcionadas ao entendimento do aluno sobre o tema sustentabilidade (grau de conhecimento quanto à preservação da natureza e a reciclagem de papel); e sete questões direcionadas a forma e ao conteúdo do material educativo a ser elaborado (colher dados que possibilitassem traçar o perfil literário dos futuros leitores).

A segunda etapa caracterizou-se pela síntese das informações coletadas na etapa anterior e elaboração do material educativo segundo indicação da maioria dos alunos entrevistados.

A terceira etapa se constitui da oficina de reciclagem de papel que ocorreu no dia 28 de maio de 2014 tendo a participação de 26 alunos do $9^{\circ}$ ano do ensino fundamental do CIEP Professor César Pernetta. A oficina teve duração de aproximadamente duas horas e as atividades foram subdivididas em duas partes:

Na primeira, o pesquisador iniciou uma atividade de ambientação, explicando os objetivos da oficina, sua função e importância no contexto de uma iniciativa de se tornar uma ferramenta para a educação ambiental de estudantes de escolas públicas. Em seguida, ofereceu o material educativo elaborado com o auxilio dos próprios alunos e explicou os principais objetivos deste material sobre reciclagem de papel. Para tanto, utilizou um áudio gravado com os conceitos relacionados à sustentabilidade, meio ambiente e preservação da natureza.

$\mathrm{Na}$ segunda parte, o pesquisador explicou todas as etapas do processo artesanal de reciclagem de papel. Os alunos foram divididos em 3 grupos (grupo 1 -10 alunos, grupos 2 e 3 - 8 alunos cada). Iniciou-se a prática da reciclagem de papel sob a supervisão e orientação do pesquisador. Para tornar a oficina mais atrativa e dinâmica, elaborou-se no final das atividades uma competição, onde cada grupo deveria executar todas as etapas da fabricação do papel 
reciclado, e venceria a competição, o grupo que fizesse mais folhas de papel reciclado, no tempo de 2 minutos.

\section{RESULTADOS}

\section{$1^{\text {a }}$ Etapa: Entrevista Semi-Estruturada com os Alunos}

A análise quantitativa dos dados permitiu traçar o perfil dos alunos participantes da pesquisa. Além disso, a análise qualitativa desses dados possibilitou a construção de um instrumento de capacitação, informação e educação voltado à educação ambiental. O objetivo da capacitação é potencializar a função social desses indivíduos num contexto onde se desenvolva a cidadania. Foi analisado o perfil dos alunos do $6^{\circ}$ ao $9^{\circ}$ ano do ensino fundamental com relação seu universo de conhecimento acerca do tema Sustentabilidade, Meio Ambiente e Reciclagem de papel. Do total de entrevistados, $72 \%$ consideram que as árvores são importantes para o meio ambiente, sendo que destes, $37 \%$ justificaram sua escolha indicando o papel da fotossíntese (oxigênio); 15\% descreveram que as árvores são importantes para o ecossistema; 11\% dos entrevistados relacionaram com a sustentabilidade do planeta e, $9 \%$ com aspectos relacionados à alimentação (frutos). Outros $28 \%$, não souberam descrever a importância ou desconhecem a questão.

Quando questionados sobre palavras que descreviam o meio ambiente, $52 \%$ citaram natureza e $5 \%$ as florestas; $17 \%$ apontaram o desperdício de água e $12 \%$ à contaminação dos rios. Para $14 \%$ a palavra que lembra meio ambiente é poluição. Percebe-se que pouco menos da metade dos entrevistados associou meio ambiente as ações danosas provocadas pelos seres humanos, isso reflete uma visão passiva e retrograda sobre as questões ambientais que já está impregnada na cultura brasileira. Depois de traçar o perfil dos entrevistados com relação ao tema sustentabilidade e suas vertentes (meio ambiente, proteção da natureza), o estudo se direcionou para o tema reciclagem.

Neste contexto, questionou-se, inicialmente, sobre a definição de reciclagem em que: $36 \%$ definiram como sendo o reaproveitamento de materiais (papel, latinha de refrigerante, garrafa pet, plástico, pilha, saco plástico), 32\% como sendo a reutilização do lixo e 14\% como a ação de não poluir e/ou melhorar o meio ambiente. Apenas, $18 \%$ não souberam ou não quiseram definir o que representava para eles a palavra reciclagem. É possível, portanto, analisar que mesmo intuitivamente, a maioria dos alunos entrevistados compreende a ideia de reaproveitar ou reprocessar materiais. Isso se deve ao fato da prática da coleta e comercialização de alguns tipos de materiais, no Brasil, serem tão usuais em determinadas regiões, principalmente, aquelas de baixa renda que a definição na maioria dos casos foi muito precisa.

Corroborando esta informação, quando questionados sobre a própria participação no envio de materiais para reciclagem, $51 \%$ afirmaram já ter realizado algum tipo de coleta seletiva para a 
reciclagem. Destes, $62 \%$ já haviam coletado latas de refrigerante/cerveja, $22 \%$ responderam papel, $7 \%$ pilha, $5 \%$ lâmpadas e $4 \%$ outros materiais, reafirmando que culturalmente as latas de alumínio e o papelão representam praticamente a totalidade de tipos de materiais enviados para reciclagem no Brasil. Portanto, houve interesse em avaliar se os entrevistados conheciam os materiais que podem ser reciclados, onde se observaram os seguintes percentuais: $25 \%$ papel, $23 \%$ plástico, $21 \%$ metal, $18 \%$ lixo orgânico e $13 \%$ vidro. Percebe-se que há uma distribuição bem estabelecida entre os diferentes materiais recicláveis, de forma que nenhum dos materiais sobressaiu frente aos demais, logo as diferentes respostas estão diretamente relacionadas a realidade cotidiana de cada um dos indivíduos. Depois de tê-los situados no universo da reciclagem, passou-se então para a reciclagem de papel propriamente dita.

Surpreendentemente, $97 \%$ dos entrevistados definiram corretamente reciclagem de papel como sendo o reaproveitamento do papel não funcional para produzir papel reciclado. Apenas $3 \%$ definiram erradamente e/ou não souberam ou quiseram definir. Além disso, $82 \%$ dos alunos entrevistados acreditam que este tipo de reciclagem é uma boa para o meio ambiente, $10 \%$ responderam que a reciclagem é boa para eles próprios e para os familiares e $8 \%$ acreditam ser interessante para as indústrias a reciclagem de papel. Neste momento, o pesquisador interveio sinalizando para os entrevistados que a prática da reciclagem de papel seria interessante para todos os setores da sociedade.

Percebeu-se que $93 \%$ dos entrevistados declararam não saber como se recicla papel. Portanto, com a intenção de saber o grau de interesse destes entrevistados no desenvolvimento de ações sustentáveis, através da prática da reciclagem de papel, observou-se que $82 \%$ dos alunos tinham interesse em realizar uma oficina de reciclagem de papel no CIEP em que estudam (Professor César Pernetta). Definiu-se que a melhor forma de aprender, para eles, era praticando (70\%) enquanto $22 \%$ acreditavam que vendo em vídeo aprenderiam melhor e apenas $8 \%$ preferiam a forma tradicional no quadro negro.

\section{$2^{a}$ Etapa: Elaboração de Material Educativo}

Buscando colaborar com o processo de transformação das pessoas, a partir da adoção de medidas que estejam ao alcance de todos, como a reciclagem de papel, foi elaborado um material que apresenta uma linguagem adequada aos jovens entre 10 e 14 anos, mostrando que a reciclagem de papel se caracteriza como uma atividade relativamente simples e indispensável para minimizar os impactos sofridos pelo planeta. A construção desta ferramenta para contribuir com a educação ambiental se deu a partir da análise qualitativa dos dados coletados no CIEP Professor César Pernetta.

Percebeu-se que um percentual expressivo de alunos desconhece os principais termos relacionados a sustentabilidade, portanto, faz-se necessário contextualizá-los e indicar a sua relevância para uma proposta de ecossistema adequado para as gerações futuras. Em síntese, sinalizar que cada uma tem um importante papel a cumprir na preservação e transformação do 
ambiente em que vive (MEDINA, 2000). De acordo com Nascimento (2011) a Educação Ambiental tem um importante papel de intermediar a reintegração homem/natureza profundamente abalada ao longo dos séculos, mediante tanto descuido e pouco caso em relação a sua preservação

Depois de contextualizá-los a respeito dos termos citados anteriormente, o material aponta os termos referentes a reciclagem, pelo fato de uma expressiva parcela do público estudado não saber o que ela representa. Outro aspecto importante é esclarecê-los sobre a importância de se fazer a reciclagem, pois se observou que a metade dos entrevistados nunca reciclou o que demonstra um total desconhecimento da importância e necessidade urgente de se preservar a natureza, a partir do reaproveitamento de materiais. É necessário esclarecer ainda, que não se faz reciclagem apenas de latas de refrigerante e/ou cerveja e papel; outros resíduos sólidos também podem ser reciclados. Portanto, esclarecê-los sobre o que são resíduos sólidos e quais deles podem ser reciclados, para que eles possam no seu cotidiano identificar materiais passíveis de reaproveitamento, coletá-los e destiná-los de forma adequada para a reciclagem.

O material educativo prevê que o educador ambiental deve procurar colocar os alunos em situações que sejam formadoras, como, por exemplo, diante de um bom exemplo de preservação ou conservação ambiental, apresentando os meios de compreensão do meio ambiente (BERNA, 2001). Por isso, a descrição de como se faz a reciclagem de papel caseira neste material, será prática, clara e de fácil compreensão e execução, despertando assim, o interesse dos alunos em fazê-la.

É desejável que o aluno quando estimulado a participar das questões ambientais torne-se um agente multiplicador de ações que beneficiarão a escola, a rua que mora e a comunidade. Estando apto para desenvolver habilidades e adotar hábitos que influenciarão em longo prazo o meio ambiente e a comunidade. Medina (2000) complementa evidenciando que alunos que constroem conhecimentos baseados em valores e comportamentos que permitam uma participação crítica, responsável e eficaz na solução de problemas ambientais, tornando-se agentes multiplicadores naturais da Educação Ambiental.

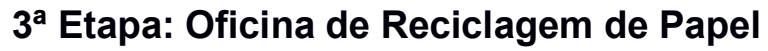

A pesquisa se apoiou na ideia que na faixa etária estudada, os estudantes se identificam com a aprendizagem a partir da prática. Demo (1997, p.28) diz que é preciso entrar no processo educativo como sujeito ativo, implicado com consciência crítica, pois a educação emancipatória não prescinde do saber crítico e criativo, porque este saber não nasce do mero ensino, ou da mera aprendizagem, mas se constrói no aprender a aprender e no aprender a pensar.

Buscando conhecer o grau de interesse dos entrevistados no desenvolvimento de ações sustentáveis através da prática da reciclagem de papel, observou-se que a proposta da realização dessa prática, a partir de uma oficina com fins de capacitação, foi muito bem aceita pela maioria 
dos alunos. Este fato contribui para que a atividade proposta tenha êxito, pois está de acordo com os anseios da população estudada.

Sato (2000) acredita que um projeto voltado para a educação ambiental de qualidade e que venha a trazer bons resultados, deve ser iniciado, com o comprometimento e a participação de toda a comunidade escolar. Esta, por sua vez, necessita entender os objetivos e a finalidade do projeto, que devem ser colocados de forma bem clara e sucinta e, só então concebê-lo como algo importante que trará inúmeros benefícios, no que tange a qualidade de vida e o desenvolvimento de toda a comunidade, dentro e fora da escola.

Dessa forma, a Educação Ambiental (EA) se configuraria, talvez, como o único destino que poderia conduzir a humanidade a adquirir a devida percepção do mundo que a cerca, a fim de examinar e julgar toda a temática que envolve o meio ambiente, resgatando então, a tão almejada qualidade de vida (SATO, 2000). Travassos (2006) corrobora com essa visão quando diz que a Educação Ambiental tem que ser praticada no dia-a-dia da escola, para que possa ser levada também para fora da mesma e para o ambiente de cada indivíduo.

Freire (1998) aborda a ideia de associar teoria e prática ou "o saber e o fazer" como a forma mais adequada da educação assumir o papel principal no processo de ensino e aprendizagem. Porém, faz-se necessário salientar que para alcançar resultados satisfatórios, as oficinas de reciclagem devem ser incorporadas a grade curricular das escolas e não serem apresentadas como uma proposta isolada e descontinuada.

Percebeu-se durante o estudo que não há uma regularidade de cursos e oficinas no ambiente desses indivíduos, pois a maioria, afirmou nunca ter participado de nenhuma. Por tanto, a reciclagem de papel segue uma lateralidade, pois somada a outras ações sustentáveis, pode em longo prazo, modificar o comportamento dos alunos a respeito da preservação do ambiente, aumentando assim, a consciência ambiental dos indivíduos, que ao experimentarem práticas sustentáveis, acabaram despertando para um comportamento mais responsável com relação aos recursos naturais.

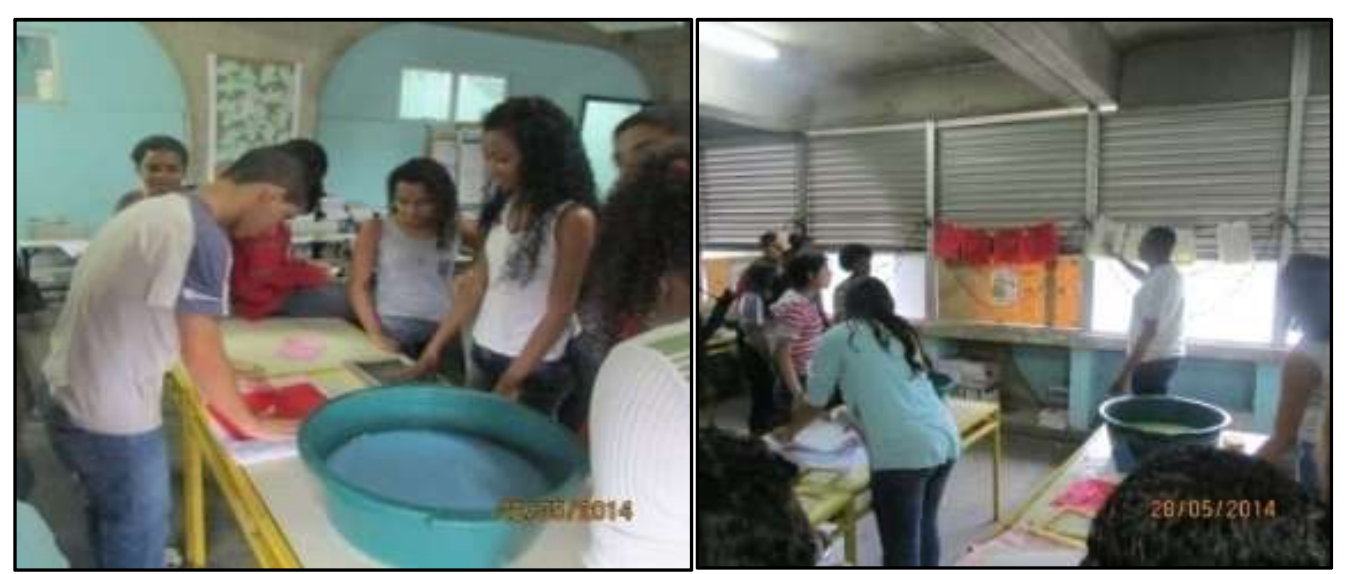

Figura 1: Oficina de reciclagem de papel com alunos do CIEP Professor César Pernetta. 


\section{CONCLUSÕES}

Partindo da premissa que o mundo se encontra num momento que converge para os ideais ambientais, e que a reciclagem de papel pode auxiliar na compreensão de que só com Educação Ambiental será possível vislumbrar um cenário favorável ao planeta, este estudo veio contribuir com uma mudança de comportamento dos indivíduos no que diz respeito à preservação e reaproveitamento de resíduos sólidos.

Todos os objetivos traçados para esta pesquisa foram alcançados. Um questionário aplicado aos alunos do $9^{\circ}$ ano do ensino fundamental do Ciep Professor César Pernetta e a análise dos dados coletados possibilitaram traçar um perfil dos alunos quanto aos conceitos relacionados a sustentabilidade e ao ambiente, além de contribuir para a elaboração de uma cartilha sobre reciclagem de papel, que pôde ser utilizada como ferramenta para a educação ambiental de alunos da rede pública de ensino. A oficina de reciclagem de papel funcionou como uma importante ferramenta para a conscientização ambiental dos alunos a respeito da preservação do meio ambiente e como instrumento de capacitação de indivíduos para a prática da reciclagem. Esta prática foi posteriormente avaliada pelos próprios alunos obtendo $100 \%$ de aprovação.

Dentre os resultados obtidos com a cartilha e a oficina de reciclagem de papel, está a percepção dos alunos da importância da coleta seletiva e reaproveitamento de materiais. Além disso, estes matérias contribuíram, significativamente, para uma mudança de comportamento dos alunos que poderão se tornar multiplicadores das práticas sustentáveis não só na escola como também na comunidade que os cerca.

\section{REFERÊNCIAS}

ADAMS, B. G.. Reciclando Conceitos. Educação ambiental em ação, v.7, 2003.

BARBOSA, M. S. S..O papel da escola: obstáculos e desafios para uma educação transformadora. Dissertação (Mestrado em Educação) - Universidade Federal do Rio Grande do Sul, Porto Alegre, 2004.

BERNA, V.. Como fazer Educação Ambiental. São Paulo: Paulus, 2001.

BRASIL. Ministério da Educação. Parâmetros curriculares nacionais: ensino fundamental. Brasília: SEF/MEC, 1999.

BRASIL. Constituição da República Federativa do Brasil de 5 de Outubro de 1988. Brasília: 5 Out 1988.

DEMO, P.. Pesquisa e construção de conhecimento: metodologia científica no caminho de Habermas. Rio de Janeiro: Tempo Brasileiro,1997.

FREIRE, P.. Pedagogia da autonomia: saberes necessários à prática educativa. 39 ed. São Paulo: Paz e Terra, 1996.

FREIRE, P.. Formação de professores. São Paulo: UNESP, 1998.

IBÁ. INDÚSTRIA BRASILEIRA DE ÁRVORES. O setor em números. Brasília: Revista IBÁ, 2014. 
LOURES, R. C. R.. Sustentabilidade XXI: educar e inovar sob uma nova consciência. São Paulo: Editora Gente, 2009.

MEDINA, N. M.. Os desafios da formação para a educação ambiental. São Paulo: Signus, 2002.

NASCIMENTO, A. G.. A reciclagem de papel como ferramenta de educação ambiental na escola estadual Nestor Lima Natal (RN). João Pessoa: Editora Universitária da UFPB, 2011.

NEVES, J. N.. Pesquisa qualitativa: Características, usos e possibilidades. Caderno de Administração. Maringá, v.1, n.3, p.1-5, 1996.

SATO, M.. Formação em educação ambiental: da escola à comunidade. Brasília: MEC, 2000.

SKINNER, B. F.. Questões recentes da análise do comportamental. Campinas: Papirus, 1991.

SOUZA, D. C.; NASCIMENTO JUNIOR, A. F.. Jogos didático-pedagógicos ecológicos: uma proposta para o ensino de ciências, ecologia e educação ambiental. In: ENCONTRO NACIONAL DE PESQUISA EM EDUCAÇÃO EM CIÊNCIAS. 5. Anais. São Paulo: ABRAPEC, 2005.

SOUZA, L. H. P.; GOUVÊA, G.. Oficinas pedagógicas de ciências: os movimentos pedagógicos predominantes na formação continuada de professores. Ciência e educação, v.12, n.3, p.303-313, 2006.

SOUZA, I. M. A.. O uso da tecnologia como facilitadora da aprendizagem do aluno na escola. Revista Fórum Identidades, Itabaiana, v.9, n.8, 2010.

TRAVASSOS, E. G.. A prática da educação ambiental nas escolas. Porto Alegre: Mediação, 2006.

VALLA, W.; STOTZ E. N.. Participação popular, educação e saúde: teoria e prática. Rio de Janeiro: Relumé-Dumará, 1993. 